\title{
EMISSIONS REDUCTIONS USING HYDROGEN FROM PLASMATRON FUEL CONVERTERS
}

\author{
L. Bromberg, D.R. Cohn, A. Rabinovich, and J. Heywood \\ Massachusetts Institute of Technology
}

\section{INTRODUCTION}

Substantial progress in engine emission control is needed in order to meet present and proposed regulations for both spark ignition and diesel engines. Tightening regulations throughout the world reflect the ongoing concern with vehicle emissions. Recently developed compact plasmatron fuel converters have features that are suitable for onboard production of hydrogen for both fuel pretreatment and for exhaust aftertreatment applications. Systems that make use of these devices in conjunction with aftertreatment catalysts have the potential to improve significantly prospects for reduction of diesel engine emissions.

Plasmatron fuel converters can provide a rapid response compact means to transform efficiently a wide range of hydrocarbon fuels into hydrogen rich gas. They have been used to reform natural gas [Bromberg1], gasoline [Green], diesel [Bromberg2] and hard-to-reform biofuels [Cohn1] into hydrogen rich gas $\left(\mathrm{H}_{2}+\right.$ $\mathrm{CO}$ ). The development of these devices has been pursued for the purpose of reducing engine exhaust pollutants by providing hydrogen rich gas for combustion in spark ignition and possibly diesel engines, as shown in Figure 1 [Cohn2]. Recent developments in compact plasmatron reformer design at MIT have resulted in substantial decreases in electrical power requirements. These new developments also increase the lifetime of the electrodes.

Compact plasmatron fuel converter technology could also be used with $\mathrm{NO}_{x}$ absorber/adsorber catalysts and particulate traps. $\mathrm{NO}_{\mathrm{x}}$ absorber catalysts and particulate traps have been suggested for the decreasing emissions from diesel and also spark ignition engines. In order to regenerate the catalyst, a reducing agent is introduced into the exhaust, either directly in-

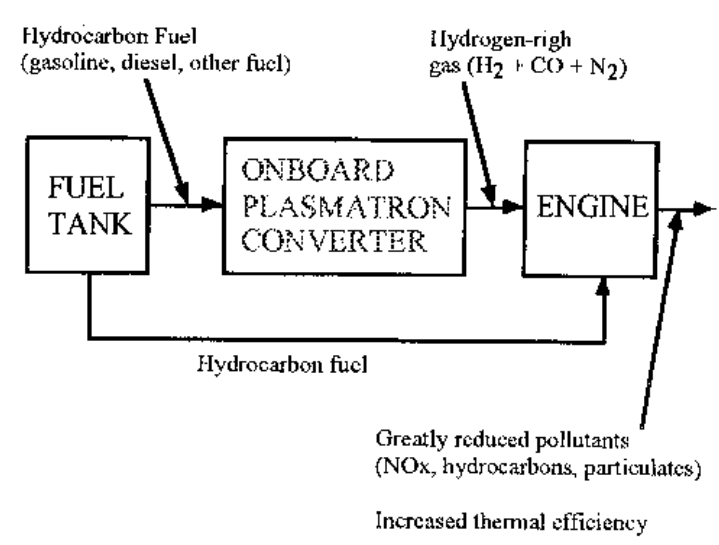

Figure 1. Low emission engine concept

jected, or in the case of spark ignition engines by running the engine fuel rich during the regenerating period. Use of compact plasmatron reformers for generating hydrogen rich gas for catalyst regeneration could provide important advantages. A schematic diagram of a plasmatron-catalyst system is shown in Figure 2.
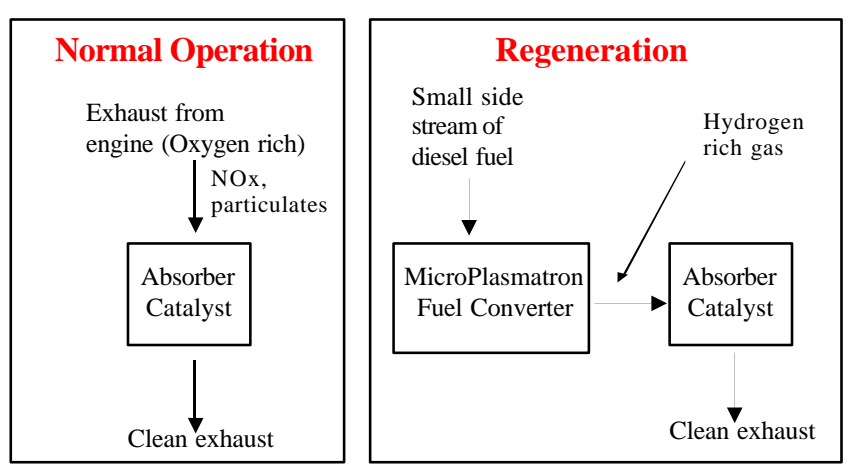

Figure 2. Diesel engine emissions aftertreatment concept

This paper summarizes possibilities for use of compact plasmatron fuel converter for onboard-hydrogen generation that could provide 
new opportunities for improved spark ignition engine and diesel engine emissions control. Substantial improvements in spark ignition engine efficiency through hydrogen enhanced lean burn operation may also be possible.

\section{Hydrogen Production from Compact Plas- matron Fuel Converter}

Plasmatron fuel converters provide electrical discharges in flowing gases of hydrocarbon fuels and air (and/or other oxidants). The resulting generation of reactive species in the flowing gases along with increased mixing accelerates reformation of hydrocarbon fuels into hydrogen rich gas. Plasmatron fuel converters may also be utilized for increasing the gas stream enthalpy, further accelerating the reaction rates. These conditions facilitate the reforming of a wide range of hydrocarbon fuels into hydrogen-rich gas.

By increasing the reaction rates, plasmatron fuel converters can reduce size requirements for effective reforming, increase speed of response and increase fuel flexibility. A wide range of fuels can be converted to hydrogen rich gas. The boost provided by the plasma can facilitate partial oxidation reactions with negligible soot production and efficient conversion of hydrocarbon fuel into hydrogen-rich gas. Plasmatron fuel converters can alleviate problems associated with catalytic reformation, such as response time limitations, sensitivity to fuel composition, poisoning, soot formation and a narrow operational temperature range.

Under ideal stoichiometric partial oxidation conditions, the partial oxidation reaction is

$$
\mathrm{C}_{\mathrm{n}} \mathrm{H}_{\mathrm{m}}+\mathrm{n} / 2 \mathrm{O}_{2} \rightarrow \mathrm{nCO}+\mathrm{m} / 2 \mathrm{H}_{2}
$$

In this case there is just enough oxygen around to convert all the carbon in the fuel into $\mathrm{CO}$. The partial oxidation reaction is exothermic. In the case of liquids fuels (gasoline, diesel), approximately $15 \%$ of the heating value of the fuel is released in the partial oxidation reaction.

The plasmatron fuel converter provides continuous ignition at the entrance of the fuel, and helps in the gasification of the fuel. By generating radicals throughout the area, limitations due to slow flame propagation are alleviated, facilitating partial oxidation reactions over the whole reactor volume, increasing conversion efficiency and reducing soot formation.

Two types of plasmatron fuel converters have been developed at MIT. One type is based on DC arc technology. These plasmatrons operate at thermal equilibrium (where the electron, ion and neutral temperatures are comparable). The temperature is high (several thousand degrees), requiring substantial electrical heating to maintain the plasma at near atmospheric pressure. This heating allows startup of partial oxidation operation at the stoichiometric oxygen to fuel ratio without the need of any additional heat provided by release of chemical energy. These compact thermal plasmas devices operate at relatively low voltages and high currents (e.g. $100 \mathrm{~V},>20 \mathrm{~A}$ and an electrical power level of $2 \mathrm{~kW}$ ). The local heating at the electrodes is high, and electrode erosion is minimized by aggressive water cooling and strong rotation of the anode root. The high power densities at the anode and cathode arc roots reduce the electrode life. Obtaining electrode life greater than 1000 hours appears to be difficult and will require new design approaches. Figure 3 shows a thermal plasmatron fuel converter. 


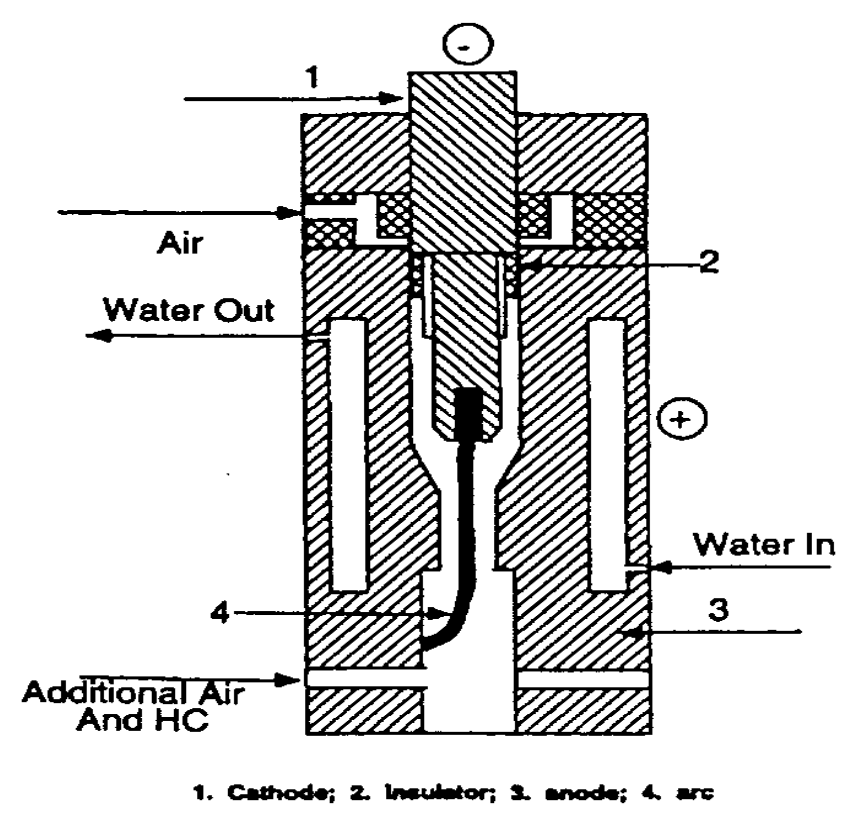

Figure 3. Thermal plasmatron fuel converter

The second type of plasmatron employs a discharge mode with non-equilibrium features allowing operation at much reduced plasma current relative to compact arc plasmatron fuel reformers previously developed at MIT. The discharge is a nonthermal plasma, with electrons at much higher temperature than the ions and neutrals, which are at near room temperature. This plasma generates relatively low levels of plasma heating. Figure 4 shows a diagram of a low current plasmatron reformer. Air and fuel are continuously injected in a plasma region provided by a discharge established across an electrode gap. The device operates at atmospheric pressure, with air as the plasma forming gas. When operating DC, the cathode can be a heavy duty spark plug. The ground electrode of the spark plug would have been removed. The anode can be a steel or copper cylinder. Neither electrode is water cooled.

Table I shows the parameters of a first generation fuel converter using a low current compact plasmatron. Typical electrical power levels are a few hundred Watts, on the order of $1-2 \%$ of the heating value power of the fuel that is processed by the plasmatron fuel converter. This electrical power loss results in a drain of 3 to $5 \%$ of the chemical power of the fuel in order to produce the electricity. Most of the heating is provided by the exothermicity of the partial oxidation reaction. The partial oxidation heating can be increased by operating with increased oxygen to carbon ratio (i.e.,

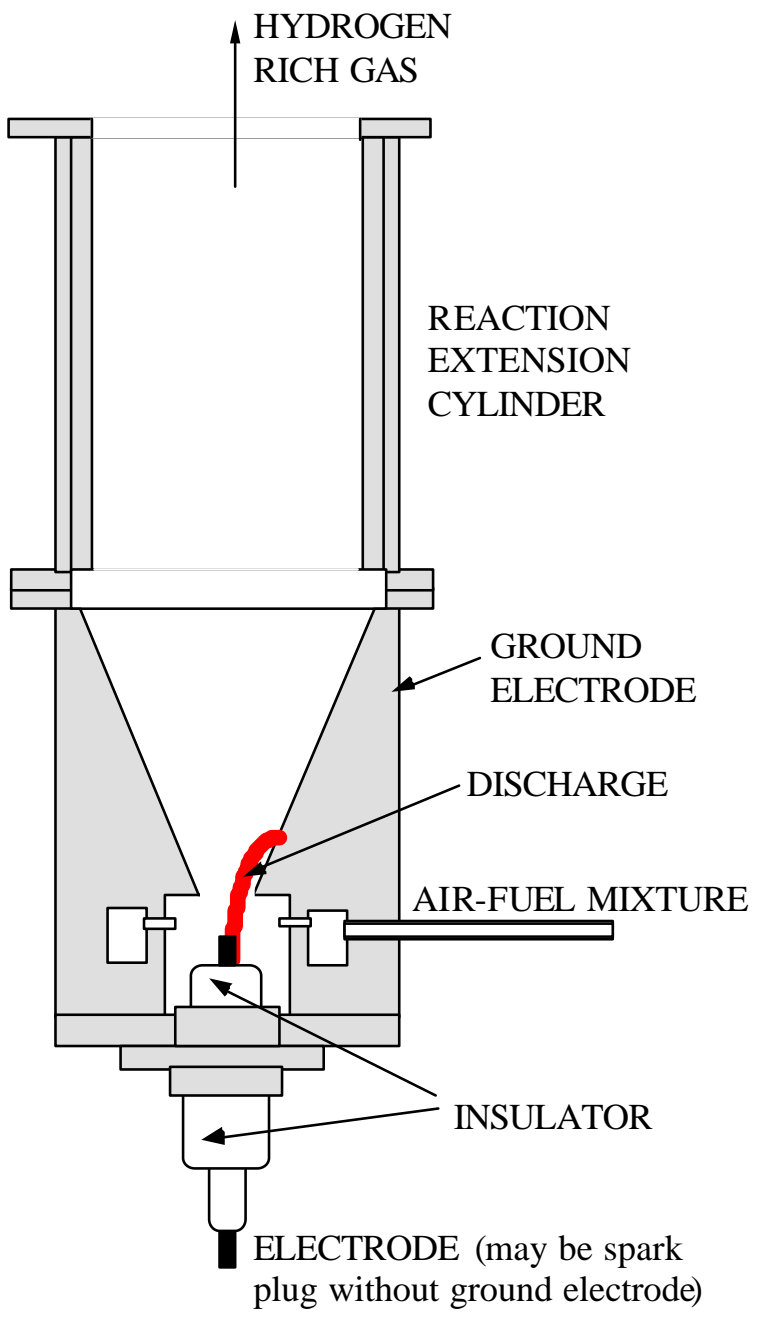

Figure 4. A low current plasmatron fuel converter.

combusting a fraction of the reformate). This additional heating is specially important during the start-up phase of the fuel converter. However, this additional heating decreases the hydrogen yield.

The plasma source is followed by a reaction extension cylinder. For tests with the addition of water, a simple heat exchanger was added downstream from the reaction extension cylinder, both to cool the reformate and to produce steam. 
Table 1.

Parameters of low current compact plasmatron fuel converter

$\begin{array}{ll}\text { Power } & 50-300 \mathrm{~W} \\ \text { Current } & 15-120 \mathrm{~mA} \\ \text { H2 flow rate } & 30-50 \text { liters/min } \\ \text { Height } & 25 \mathrm{~cm} \\ \text { Volume } & 2 \text { liters } \\ \text { Weight } & 3 \mathrm{~kg}\end{array}$

Second generation low current plasmatron fuel converters have recently been tested. In these compact devices both the cathode and the anode have relatively large area, in contrast to the first generation device shown in Figure 2. They produce a discharge over a relatively large volume and have been operated at signifycantly higher powers than the first generation low current plasmatrons. This type of low current device has been used to convert natural gas, gasoline and diesel fuel into hydrogen rich gas. There was minimal evidence of soot production in the processing of diesel fuel, even after extended operation. Typical power conversion efficiencies in the partial oxidation mode were $60-85 \%$ (ratio of heating value of the product gas to heating value of the fuel). Diesel fuel streams with chemical power levels of 5 to 20 $\mathrm{kW}$ have been processed into hydrogen rich gas.

Table 2 shows reforming results for several cases, using the second generation plasmatron fuel converters, at steady state conditions (after about 1 to 2 minutes). Several types of reaction extension cylinders were used with either no catalyst or a catalyst in the reaction extension cylinder. The effect of the presence of water was also studied. The purpose of the water addition is to convert, via a water-shift reaction, a large fraction of the $\mathrm{CO}$ generated in the plasmatron fuel converter into additional hydrogen, for those applications were hydrogen is much more preferred than $\mathrm{CO}$. Hydrogen yields higher than $100 \%\left(\mathrm{H}_{2}\right.$ in product gas divided by hydrogen in fuel) can be achieved with the use of a catalyst and water shifting. Power conversion efficiencies of close to $90 \%$ have also been obtained under certain conditions. However, it is difficult to provide the required water onboard vehicles, and this issue could be a major deterrent to the use of the water shift reaction for onboard applications for internal combustion engines.

Typical second generation low current plasmatron fuel converter parameters were at power levels of $300 \mathrm{~W}$ to $600 \mathrm{~W}$, and oxygen/carbon ratios $(\mathrm{O} / \mathrm{C})$ of $1.2-1.5$, and fuel rates of $0.3-0.5$ $\mathrm{g} / \mathrm{s}$ (corresponding to about $10-20 \mathrm{~kW}$ of fuel power).

The composition of the hydrogen rich gas for the cases in Table 2 are shown in Table 3. High concentrations of hydrogen and $\mathrm{CO}$ are obtained. It appears to be possible to operate the low current plasmatron fuel converter in modes with minimal production of soot.

The startup yield of the plasmatron fuel converter has been investigated with both diesel and gasoline fuel. The composition of the hydrogen rich gas was studied as a function of time. Hydrogen yields as high as $30 \%$ are instantaneously obtained (in times less than 3 seconds), increasing to as high as $80 \%$ after 90 seconds. The power conversion efficiency is about $30 \%$ at startup, increasing to $70-80 \%$ after the reactor has warmed up. Similar performance has been obtained in both fuels. 
Table 2.

Performance of second generation low current plasmatron fuel converter using diesel fuel Cases for different catalysts, $\mathrm{O} / \mathrm{C}$ ratios and presence/absence of additional water.

$\begin{array}{lcccccccc} & \begin{array}{c}\text { Electrical } \\ \text { Power input } \\ \mathrm{kW}\end{array} & \begin{array}{c}\mathrm{O} / \mathrm{C} \\ \text { ratio }\end{array} & \mathrm{H} 2 \mathrm{O} / \mathrm{C} & \begin{array}{c}\text { Fuel } \\ \text { Flow rate } \\ \mathrm{g} / \mathrm{s}\end{array} & \begin{array}{c}\text { Fuel } \\ \text { Power } \\ \mathrm{kW}\end{array} & \begin{array}{c}\text { Hydrogen } \\ \text { yield }\end{array} & \begin{array}{c}\text { Energy } \\ \text { ConsumptionEfficiency } \\ \text { MJ/kg }\end{array} & \begin{array}{c}\text { Power } \\ \%\end{array} \\ \begin{array}{c}\text { Empty reactor } \\ \text { no water }\end{array} & 0.27 & 1.32 & 0 & 0.26 & 11 & 0.64 & 13 & 56 \\ \begin{array}{c}\text { Ceramic catalyst } \\ \text { no water } \\ \text { Honeycomb catalyst } \\ \text { no water }\end{array} & 0.19 & 1.51 & 0 & 0.48 & 20 & 0.75 & 4 & 64 \\ \begin{array}{c}\text { Honeycomb catalyst } \\ \text { with water }\end{array} & 0.23 & 1.21 & 0 & 0.34 & 14 & 0.91 & 6 & 74 \\ \quad & 0.15 & 1.24 & 1.78 & 0.31 & 13 & 1.22 & 3 & 87\end{array}$

Table 3.

Gas composition for cases in Table 2.

$\begin{array}{lcccccc} & \begin{array}{c}\mathrm{H} 2 \\ \text { vol.\% }\end{array} & \begin{array}{c}\mathrm{CO} \\ \text { vol.\% }\end{array} & \begin{array}{c}\mathrm{CO} 2 \\ \text { vol.\% }\end{array} & \begin{array}{c}\mathrm{N} 2 \\ \text { vol.\% }\end{array} & \begin{array}{r}\mathrm{CH} 4 \\ \text { vol.\% }\end{array} & \begin{array}{c}\mathrm{C} 2 \mathrm{H} 4 \\ \text { vol.\% }\end{array} \\ \begin{array}{l}\text { Empty reactor } \\ \text { no water }\end{array} & 14 & 16 & 4.7 & 64 & 0.7 & 0.1 \\ \begin{array}{c}\text { Ceramic catalyst } \\ \text { no water }\end{array} & 14 & 17 & 4.7 & 64 & 0.2 & 0 \\ \begin{array}{c}\text { Honeycomb catalyst } \\ \text { no water }\end{array} & 19 & 21 & 3.3 & 57 & 0.3 & 0 \\ \begin{array}{c}\text { Honeycomb catalyst } \\ \text { with water }\end{array} & 23 & 17 & 6.2 & 52 & 1.2 & 0.4\end{array}$

Previously, diesel fuel has been successfully reformed at $\mathrm{O} / \mathrm{C} \sim 1$ using a compact plasmatron reformer that employs a DC arc plasmas [Bromberg2]. However, arc plasmatron reforming utilizes substantially higher electrical powers and currents.

\section{Reduction of spark ignition engine emis- sions}

The availability of hydrogen rich gas onboard a vehicle allows very lean spark ignition engine operation. Hydrogen rich gas significantly increases flame speed, thereby extending the lean region of engine operation without misfire. Very lean operation has been shown to substantially decrease emissions and to also increase efficiency [Breashers, Houseman, Grieve]
For $\mathrm{NO}_{x}$ reduction in a spark ignition engine, the hydrogen rich gas produced by the plasmatron fuel converter is used as an additive. In this case, a fraction of the fuel is processed by the plasmatron fuel converter, and injected into the cylinder with the air. The hydrogen rich gas facilitates diluted engine operation, with either very lean or heavy EGR (exhaust gas recirculation) operation. The dilution increases the thermal capacity of the air/fuel mixture, decreasing the peak combustion temperatures and dramatically decreasing the $\mathrm{NO}_{x}$ emissions. This approach is particularly attractive in state of the art gasoline and natural gas engines where only a relatively modest amount of hydrogen may be necessary to allow very lean operation without any misfire. [Bromberg4] 
Figure 5 shows the results of $13 \%$ hydrogen addition by heating value to a gasoline engine in a test stand. A first generation low current plasmatron fuel converter with a hydrogen yield of around $75 \%$ was employed. For this hydrogen yield it was necessary to process about $35 \%$ of the fuel in the plasmatron fuel converter in order to obtain a $13 \%$ hydrogen addition.

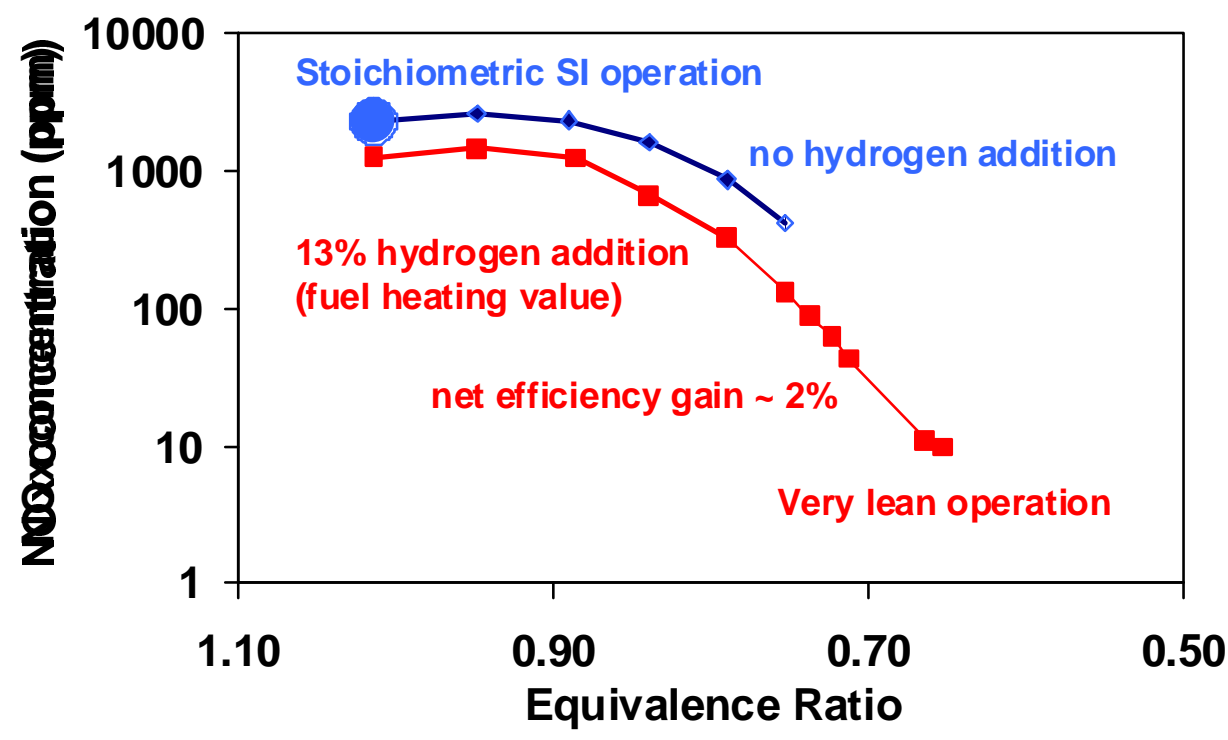

Figure 5. Engine tests with hydrogen rich gas from microplasmatron fuel converter

Substantial increases in overall efficiency in spark ignition engines may be possible with minimization of hydrogen requirements in state of the art engines, high plasmatron fuel converter power conversion ratios and optimization of the engine for very lean, high compression ratio, open throttle operation. [Bromberg4] Very lean high compression ratio, open throttle operation should provide a gross engine efficiency similar to that of a diesel engine. The net efficiency will be lower because of the power loss due to plasmatron fuel converter operation. This power loss is represented by a power conversion efficiency that takes into account both exothermic power loss and the electrical power requirement of the plasmatron (converted into the chemical power required to produce the electrical power). For example, if only $25 \%$ of the fuel is processed by the plasmatron fuel converter and the power conversion efficiency is 0.80 , the net engine efficiency is equal to the engine efficiency times a factor of $0.95(=0.75$ $+0.25^{\star} 0.80$, which represents the reduction in available fuel power). If the gross engine efficiency of a hydrogen-addition lean burn gasoline engine is similar to that of a diesel engine, the net efficiency would be $95 \%$ of that of a diesel engine. For example, for a gross engine efficiency of $42 \%$, the net engine efficiency would be $41 \%$. As is analogous to the case with diesel engines, the low specific power resulting from ultra lean operation in this spark ignition engine could be alleviated by boosting by turbocharging or supercharging. Extensive investigation is needed to assess the possibility if achieving such high net spark ignition engine efficiencies.

\section{Exhaust Aftertreatment using Absorber Catalysts}

An absorber catalyst can be used for first trapping the $\mathrm{NO}_{x}$ in diesel engine exhaust. The catalyst can then be regenerated by the use of 
highly reducing hydrogen and $\mathrm{CO}$ from the plasmatron fuel converter. The catalyst for $\mathrm{NO}_{x}$ treatment is very sensitive to poisoning by sulfur. In order to solve this problem, a sulfur trap is under development [Parks1], in conjunction with the development of $\mathrm{NO}_{\mathrm{x}}$ absorber catalysts.

Experimental studies of combined $\mathrm{SO}_{\mathrm{x}}$ and $\mathrm{NO}_{x}$ traps have been carried out by Goal Line Technologies [Parks1, Parks2]. These investigations examined both the use of diesel fuel and hydrogen as reducing agents for trap regeneration. Greater than $90 \% \mathrm{NO}_{x}$ removal was obtained. Further work is needed to determine effects of sulfur on catalyst lifetime and the differences in the use of diesel fuel and hydrogen rich gas for catalyst regeneration.

Goal Line Environmental Technologies has claimed a $98.9 \%$ reduction in $\mathrm{NO}_{x}$ and Hydrocarbon $(\mathrm{HC})$ emissions from diesel engines. Employing their catalyst system with a Cummins 50-kW/86-bhp diesel engine, $\mathrm{NO}_{x}$ and $\mathrm{HC}$ have been reduced to 0.4 grams per brake horsepower-hour ( $\mathrm{g} / \mathrm{bhph}$ ), an emissions reduction that is an order of magnitude lower than the U.S. EPA's 2002 emission reduction requirement ( $4.0 \mathrm{~g} / \mathrm{bhph}$ for diesel engines).

A similar process may be used for trapping/ regenerating particulates. The harmful or noxious emissions can be trapped in one system, and then released and treated in a downstream unit (engine or another catalyst).

A Daimler Benz group [Boegner] has developed a concept br the regeneration of one of the catalyst while the other is in the adsorbing mode. This concept uses a motor vehicle exhaust emission control system that has tandem adsorber catalysts connected in parallel for alternate adsorption and desorption. $\mathrm{NO}_{\mathrm{x}}$ from the engine goes to the operating adsorber catalyst while the other adsorber catalyst is in the desorption mode. An oxidizing converter is located upstream of the adsorber part and near the engine in order to oxidize the $\mathrm{NO}$ contained in the exhaust to form $\mathrm{NO}_{2}$, so as to permit an increase in the $\mathrm{NO}_{x}$ adsorption rate for the ni- trogen adsorber parts. A reducing agent is used to regenerate the catalysts.

The use of compact plasmatron fuel converters in systems for regeneration of these catalysts could provide a number of significant advantages. Hydrogen rich gas is a significantly stronger reducing agent than diesel or gasoline. Use of hydrogen rich gas could potentially provide:

- Higher regeneration effectiveness

- Larger regeneration operating window

- Reduced poisoning of catalyst (since diesel fuel is not used for regeneration)

- Reduced emissions of hydrocarbons, since it is easier to prevent release of hydrogen and $\mathrm{CO}$ than hydrocarbons due to faster catalytic removal

- Reduced loss in overall fuel efficiency due to lower requirements on amount of reducing gas and greater ease of reuse of hydrogen rich gas in the engine.

- Shorter regeneration time due to greater reducing capability of hydrogen rich gas and high concentration of reducing gases.

Compact plasmatron reformers are well suited for the required hydrogen-rich gas generation for reasons discussed earlier. Use of the plasmatron allows for efficient reforming at the low throughputs required for the aftertreatment application. Moreover, the hot gas from the compact plasmatron fuel converter might be used for catalyst warm-up (decreasing the lightoff time) or for catalyst heating during regeneration.

The devices described above could also be used, with a modification of the absorber catalyst, to treat other emissions. It may be useful to employ a system that uses a particulate trap that is regenerated by the injection of hydrogen rich gas, with or without an oxidant. In this embodiment, the hydrogen rich gas could also be used, along with some free oxygen, for burning the particulates deposited in the particulate trap. Or if the temperature of the trap is high enough, it could be used for gasification of the particulate, without the use of an oxidant. The absorbing and or gasification processes could be either homogeneous or catalytic in nature. 
Table 4

Compact plasmatron fuel converter/absorber system Illustrative parameters

\author{
Engine NOx production \\ Engine power \\ Engine NOx rate \\ Average hydrogen rate

\section{Low current \\ Electrical power \\ Diesel fuel to plasmatron \\ Average chemical power of diesel fuel to Flret to plasmatron/fuel to engine}

Illustrative parameters for a compact plasmatron fuel converter system regenerating an absorber catalyst are shown in Table 4 . It is assumed that the hydrogen throughput requirements are three times stoichiometric, and that the $\mathrm{CO}$ that is produced in the compact plasmatron fuel converter does not help reduction in the catalyst. Hence, there is a margin of a factor of 6 in the flow rate of reducing agent relative to the best possible conditions. The actual amount needs to be experimentally determined. Based on the illustrative parameters in Table 4, if all of the chemical energy in the fuel used for regeneration were lost, the loss in chemical energy would be around $2 \%$ of the fuel used by the engine to generate mechanical power. The required hydrogen-rich gas generation level has been demonstrated in initial tests by the use of low current plasmatron fuel converters for conversion of diesel fuels.

\section{Conclusions}

$\mathrm{NO}_{\mathrm{x}}$ and particulate absorber/adsorber catalysts are promising technologies for controlling emissions from diesel engines. Prospects for successful use may be significantly enhanced by systems which combine these technologies with compact plasmatron fuel converters. The requirements on the compact plasmatron fuel converter have been evaluated, and it has been determined that the requirements for the compact plasmatron fuel converter are modest. Large windows for regeneration temperatures and short regeneration times, with low duty cycle, may well be attainable. Although this paper focuses on applications involving absorber/adsorber catalysts in diesel engines, the use of a compact plasmatron fuel converter for pro-

$\begin{array}{lrrr}\text { g/bhp-hr } & 2 & 2 & 2 \\ \text { hp } & 100 & 200 & 400 \\ \text { g/hr } & 200 & 400 & 800 \\ \text { g/hr } & 40 & 80 & 160 \\ \text { I/min } & 7.5 & 14.9 & 29.9\end{array}$

$\begin{array}{lccc}\mathrm{g} / \mathrm{hr} & 316 & 632 & 1265 \\ \mathrm{~kW} & 3.5 & 7.0 & 14.1 \\ & 2.1 \% & 2.1 \% & 2.1 \%\end{array}$

duction of hydrogen rich gas for regeneration may have other applications. A key feasibility issue is the effect of sulfur on catalyst operation.

Plasmatron fuel converters might also be used to reduce $\mathrm{NO}_{\mathrm{x}}$ from spark ignition engines using gasoline or natural gas. Factors of 10 reduction are possible through lean operation. It may also be possible to substantially increase net spark ignition engine efficiencies with lean, high compression ratio, open throttle operation. Under certain conditions it may be possible to increase net engine efficiency to $95 \%$ that of a diesel engine. Extensive investigation is needed to assess the feasibility of obtaining such substantial increases in engine efficiency.

Both DC arc plasmatron fuel converters and low current plasmatron fuel converters can be operated with low average electrical power requirements. Use of highest electrical power levels only during plasmatron fuel converter startup and transients can substantially reduce average power requirements. Future directions for plasmatron fuel converter development include soot minimization and further reductions in size and startup times.

\section{References}

[Boegner] INTERNAL COMBUSTION ENGINE EXHAUST EMISSION CONTROL SYSTEM WITH ADSORBERS FOR NITROGEN OXIDES THE USE OF TANDEM CATALYSTS, W.H. Boegner, K. Karl-Ernst, V. Bernd, et. al., US Patent US 5910097, issued 06/08/1999; assignee: Daimler Benz 
[Breashers] Partial Hydrogen Injection into Internal Combustion Engines - Effect on Emissions and Fuel Economy, R. Breashers, H. Cotrill and J. Rupe, presented at the First Symposium on Low Pollution Power Systems Development, Ann Arbor MI (1973)

[Bromberg1] Plasma Catalytic Reforming of Methane, L. Bromberg, D.R. Cohn, A. Rabinovich and N. Alexeev, Int. J. Hydrogen Energy 24 (1999)

[Bromberg2] Plasma Reforming of Diesel Fuel, L. Bromberg; A. Rabinovich; N. Alexeev; and D.R. Cohn, Plasma Science and Fusion Center Report PSFC/JA-99-4 (presented at the National Meeting of the Americ an Chemical Society, Annaheim, CA March 1999)

[Bromberg3] L. Bromberg, D.R. Cohn, A. Rabinovich, Aftertreatment of Diesel Vehicle Emissions Using Compact Plasmatron Fuel Converter-Catalyst Systems, to be published, Int. Journal of Vehicle Design

[Bromberg4] Compact Plasmatron Boosted Hydrogen Gnereration Technology for Vehicular Applications, L. Bromberg,. D.R. Cohn, A. Rabinovich, J.E. Surma and J. Virden, International Journal of Hydrogen Energy, 24, 341-350 (1999)

[Cohn1] Onboard Plasmatron Reforming of Biofuels, Gasoline and Diesel Fuel, D.R. Cohn, A. Rabinovich, L. Bromberg, J.E. Surma and J. Virden, presented at the Future Transportation Technology Conference \& Exposition, Costa Mesa, CA (1998); SAE- 981920

[Cohn2] Near Term Possibilities for Extremely Low Emission Vehicles using On-Board Plasmatron Generation of Hydrogen, D.R. Cohn, A. Rabinovich, C.H. Titus and L. Bromberg, International Journal of Hydrogen Energy, 22, 715 (1997) [Green] Experimental Evaluation of SI Engine Operation Supplemented by Hydrogen Rich Gas from a Compact Plasma Boosted Reformer, J.B. Green, L. Bromberg, D.R. Cohn, et. al., presented at the Government/Industry Meeting,
June 2000, Washington, DC, USA; SAE-200001-2206; also PSFC Report JA-99-32

(November 1999)

[Grieve] Integration of a Small On-board Reformer to a Conventional Gasoline Internal Combustion Engine System to Enable a Practical and Robust Near-Zero Emission Vehicle, M.J. Grieve, J.E. Kirwan and A.A. Quader, presented at the 1999 Global Powertrain Conference, Stuttgart Germany (Oct 1999)

[Houseman] A Two Charge Engine Concept: Hydrogen Enrichment, J. Houseman and F.W. Hohn, SAE paper 741169 (1974)

[Parks1] J.E. Parks, L.E. Campbell, G. J. Wagner, W. E. Epling and M. S. Sanders, SCOTM and SCOSO $\mathrm{TM}_{x}$ Sorbate Catalyst System for the Aftertreatment of $\mathrm{NO}_{2}$ Diesel Exhaust, SAE paper 1999-01-3557; see also http://www.glet.com/update_10-99.htm\#CUMMINS

[Parks2] James E. Parks, G. J. Wagner, W. E. Epling, M. S. Sanders and Larry E. Campbell, Near Zero Control for Diesel Aftertreatment, SAE paper 1999-01-2890. 